\title{
Ley 5/2011, de 29 de marzo, de Economía Social: ¿su aplicación es cosa de todos? (pregunta retórica)
}

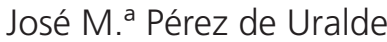 \\ Director del Observatorio Vasco de Economía Social-OVES \\ Vicepresidente de CIRIEC-España
}

Sumario: I. Aplicación en el ámbito estatal. II. Aplicación en el ámbito autonómico. País Vasco.

Resumen: En este artículo se trata de analizar los pasos que deben darse, tanto en el ámbito estatal como en el autonómico, para lograr la aplicación efectiva de la Ley de Economía Social.

Palabras clave: Ley de Economía Social y su aplicación efectiva.

Abstract: This article focuses on analysing the steps which should be taken at the national and autonomous community levels to effectively implement the Law of Social Economy.

Keywords: Law of Social Economy and its effective implementation. 


\section{Aplicación en el ámbito estatal}

La entrada en vigor de la Ley 5/2011, de 29 de marzo de Economía Social (BOE de 30 de marzo de 2011) ha suscitado ya relevantes análisis desde el punto de vista dogmático, así como comentarios mayoritariamente positivos provenientes de instituciones y agentes del sector ${ }^{1}$.

Pero la inicial satisfacción manifestada desde hace un año por parte de los implicados e interesados en su aplicación, puede empezar a mostrar signos de agotamiento si no se dan pasos adelante en su cumplimiento efectivo. Sobre cómo empezar a cumplirla ya se están dando algunas ideas ${ }^{2}$, pero no se advierten decisiones consolidadas.

La intención de estas reflexiones que ahora sometemos al debate, en esta oportunidad que nos brinda la Universidad de Deusto, tiene que ver precisamente con esta necesidad de ir moviendo ficha. Al tiempo, y refiriéndonos a la Comunidad Autónoma del País Vasco, pretendemos destacar algunos datos sobre esta concreta cuestión.

En líneas generales las opiniones con respecto a esta Ley se concentran en la importancia de su promulgación. Es decir, el que se haya colmado una necesidad y una aspiración largamente constatada: incorporar la Economía Social de un modo directo y autónomo al universo legal formal. Se supera así una extravagancia, no infrecuente, que ha hecho que el término Economía Social y lo que significa, a pesar de no estar definido legalmente, sin embargo, fuera objeto desde hace mucho tiempo de regulación legal explícita en leyes, decretos, órdenes ministeriales y de las Comunidades Autónomas (CCAA), estructuras administrativas gubernamentales, designación de cargos públicos y asignaciones de partidas presupuestarias y subvenciones de diverso tipo.

Por ello, que exista una definición legal del término, guste ésta más o menos, es un avance, y haber quedado plasmado en una norma con rango de Ley qué es lo que específicamente forma parte de la Economía Social, es un hecho también importante. Un avance indiscutible en términos de seguridad jurídica y una oportunidad indudable para proyectar su visibilidad y legitimación institucional. Pero las presentes líneas no se dirigen a analizar el texto ni sus consecuen-

1 Pérez de Uralde, José M. ${ }^{a}$ : «Algunas consideraciones sobre la repercusión de la Ley 5/2011, de 29 de marzo, de Economía Social, en la Comunidad Autónoma de Euskadi». En Revista Vasca de Economía Social, n. ${ }^{\circ}$, pp. 37 a 61. Edit. GEZKI-UPV/EHU y Gobierno Vasco. Bilbao, 2012.

2 Pérez de Uralde, José M. ${ }^{\text {a: }}$ opus cit. 
cias prácticas o formales, sino a constatar un muy negativo retraso en su aplicación real.

El texto legal tiene aspectos destacables por su oportunidad y necesidad, pero también adolece de una cierta falta de concreción en cuanto a las medidas de promoción y fomento que defiende. Los expertos señalan que técnicamente es mejorable y se constata que su estructura técnico-jurídica empeoró al modificarse el texto propuesto por la Comisión de Expertos liderada por el CIRIEC-España ${ }^{3}$. Pero con todo, resulta indiscutible que es una herramienta de primer orden que abre enormes expectativas para el desarrollo de las figuras que componen la Economía Social española y las entidades que las representan.

Lo que pasa es que nos estamos encontrando, casi año y medio después de su entrada en vigor, con la evidencia algo preocupante ya anunciada antes: la Ley no se está aplicando y apenas se la tiene en cuenta en la labor legislativa a ella vinculada. Si esta norma nació con cierta algarabía y optimismo parece que a partir de los primeros momentos se ha visto afectada por un ataque de somnolencia que la mantiene en un sueño pacífico. Quizá se pretende no despertarla de golpe en estos momentos y se opta por no aplicarla, ni tan siquiera en los mandatos temporales que su texto incorpora, como veremos.

Esta situación letárgica puede deberse a varias causas (que no son objetivo inmediato de estas líneas), pero no puede mantenerse por más tiempo si se pretende impedir que propicie la indolencia y la marginalidad. Las dos principales funciones que por lo general se atribuyen a esta Ley tienen que ver con lo ya dicho de reconocimiento legal y, también, con su carácter de instrumento para el fomento y promoción. Estos aspectos declarativos pueden estar propiciando precisamente que se considere secundario cumplir alguno de los mandatos directos que incorpora. Al ser una Ley que no regula las entidades que la componen, pues cada una tiene su propia normativa de aplicación (artículo 1), no genera necesidades inmediatas para ellas, salvando la referencia a la reforma de la Ley de Sociedades Laborales incorporada en su Disposición adicional séptima, incumplida hasta la fecha. Pero la preponderancia de este carácter entre constitutivo y declarativo que caracteriza a la Ley puede acabar mermando su credibilidad y hacer pensar que su

3 Monzón Campos, José Luís (director): Informe para la elaboración de una Ley de Fomento de la Economía Social. Ministerio de Trabajo e Inmigración. Madrid 2010. Paz Canalejo, Narciso: Comentario sistemático a la Ley 5/2011, de Economía Social. Edit: Tirant lo Blanch, Reformas. Valencia, 2012. 
creación ha sido un acto estricto de política de visibilización sin contenido concreto. Falta de credibilidad deudora fundamentalmente de la propia inaplicación de las escasas medidas que incorpora con señalamiento de plazo cierto y obligado.

Una razón que está en mente de todos y que explicaría lo que está sucediendo se sitúa en ese gran «tótem» que nos tiene obnubilados llamado "crisis económica-financiera». Es verdad que la situación es gravísima y que lo está paralizando todo. También la aplicación de las normas legales, desde la Constitución (CE) hasta la más humilde de las Órdenes administrativas. Pero estamos en un Estado de Derecho (Preámbulo y artículo 1 CE) y no nos consta que se hayan adoptado medidas de carácter extraordinario de supresión o suspensión de Derechos Fundamentales o relativos a la aplicación de las normas jurídicas vigentes. Queremos decir que la aplicabilidad de la Ley no puede depender exclusivamente de coyunturas ajenas a su propia naturaleza o causa. La actual crisis está demostrando muchas cosas y una muy relevante es que las entidades y empresas de la Economía Social ofrecen un grado de resistencia superior al del resto de sectores, contribuyendo a paliar los efectos devastadores de la crisis y de las medidas adoptadas para combatirla. La coyuntura, ante estas evidencias, no puede servir de excusa o motivo para no cumplir con las previsiones de la Ley 5/2011. Primero, insistimos, porque la promoción y fomento de la Economía Social en estos tiempos puede ser de la máxima utilidad y, segundo, porque las disposiciones de la Ley son imperativas, especialmente las que incorporan plazos.

Además, hemos de resaltar que la mayoría de las determinaciones con plazo de la Ley no parecen estar afectadas por obstáculos impedientes o cuya ejecución pueda redundar en menoscabo de la situación que afrontamos. Más bien al contrario. Pongamos algunos ejemplos.

\section{El Consejo para el Fomento de la Economía Social}

El artículo 9 prevé que este Consejo se regirá por lo «...dispuesto en esta Ley» atribuyéndole funciones de asesoramiento y consulta sobre cuestiones muy relevantes para la Economía Social como sector. Además, este artículo señala que «El funcionamiento y composición del Consejo será objeto de desarrollo reglamentario...». Tal desarrollo no se ha producido. Técnicamente la falta de elaboración del nuevo reglamento del Consejo para el Fomento de la Economía Social no impide adoptar las medidas que de él dependen pues la Disposición transitoria 
primera establece que el Consejo, en tanto se desarrolla su nuevo reglamento, se regirá por el actual, derivado de la Disposición adicional segunda de la Ley 27/1999, de 16 de julio, de Cooperativas. Es decir, por la normativa que rige su funcionamiento actualmente.

Sería bueno conocer cuál va a ser la política que se pretende seguir con respecto a este tema, si la de proceder a elaborar el nuevo reglamento como prioridad, o mantener su actual estructura de modo transitorio pero operativo o, por fin, no hacer nada. Para nosotros es urgente constituir un Consejo de Fomento de la Economía Social sincrónico con la Ley, acorde a su mandato y a sus inmediatos cometidos.

\section{El catálogo del artículo 6 de la Ley 5/2011}

El artículo 6 de la Ley prevé la elaboración de un catálogo actualizado de los diferentes tipos de entidades integrantes de la Economía Social, lo que habrá de hacerse de forma coordinada con los catálogos autonómicos. Dichos elencos deberán ser públicos, dice la norma. Pero pasado año y medio desde su entrada en vigor, nada se ha hecho con respecto a este tema. No hay catálogos oficiales, ni a nivel estatal y en el ámbito de las CCAA. Podría vincularse este incumplimiento, consolidando así un auténtico circulo vicioso, con la falta descrita de reforma del Consejo de Fomento de la Economía Social, ya que según el citado artículo 6 el catálogo estatal deberá elaborarse previo informe del citado Consejo y, también, de las CCAA (las cuales, por cierto, deberán decidir qué mecanismos articulan a partir de ahora para cumplir con efectividad y consenso su participación en las decisiones que por la Ley les compete.) Pero sería una explicación poco seria.

\section{Disposición adicional primera}

Sobre información estadística relativa a las entidades de la Economía Social. A su vez, están pendientes de adoptar las medidas que en este capítulo establece la Ley, las cuales precisan también de pronunciamiento previo del Consejo para el Fomento de la Economía Social4

${ }^{4}$ La Disposición adicional primera de la Ley 5/2011 dice textualmente: «Información estadística sobre las entidades de la economía social. El ministerio de Trabajo e Inmigración adoptará, en colaboración y coordinación con los departamentos ministeriales y las Administraciones que pudieran tener competencia en materia registral de las entidades 


\section{Disposición adicional séptima}

Sobre aprobación de un programa de impulso de las entidades de Economía Social por parte del Gobierno, para el que se da un plazo específico de 6 meses para su cumplimiento. Dicho programa incluye tres previsiones:

1. Previa consulta a las entidades representativas de la economía social, del Consejo para el Fomento de la Economía Social y de las Comunidades Autónomas, revisará la normativa necesaria para eliminar las limitaciones de las entidades de la economía social, de forma que estas puedan operar en cualquier actividad económica sin trabas injustificadas.

2. Previa consulta a las entidades representativas de la economía social, del Consejo para el Fomento de la Economía Social y de las Comunidades Autónomas, remitirá a las Cortes un proyecto de ley que actualice y revise la Ley 4/1997, de 24 de marzo, de sociedades laborales.

3. Previa consulta con las entidades que realizan acción social revisará la normativa de desarrollo de la Ley 38/2003, de 17 de noviembre, General de Subvenciones, que le es de aplicación, con el objeto de simplificar los procedimientos regulados en la misma.

La finalidad de este breve trabajo se limita a constatar la congelación de estas previsiones, las cuales son de carácter estrictamente legislativo y de enorme trascendencia práctica para los sectores y entidades afectadas. Su aplicación inmediata es lo que da verdadero sentido práctico a esta Ley y lo que ha justificado gran parte de su aceptación. Está claro que determinadas normas legales incorporan un componente declarativo de la mayor importancia y que no se inscribe en el ámbito de las aplicaciones automáticas de lo preceptuado. Pero los mandatos concretos y a plazo fijo si no se cumplen pueden generar descrédito y decepción. Las valoraciones sobre la importancia de la aprobación de la Ley no podrán mantenerse por mucho tiempo si perdura la falta de aplicación de su parte dispositiva. Por ello, se hace preciso abordar sin demasiada demora las determinaciones más visuales y operativas: reforma del reglamento para el Consejo para el Fomento de la Economía Social y su rápida constitución; elaboración del catálogo de entidades;

de la economía social, y previo informe del Consejo para el Fomento de la Economía Social, las medidas necesarias para garantizar una información estadística de dichas entidades así como de sus organizaciones de representación, periódicamente actualizada y ajustada en su clasificación al catálogo previsto en el artículo 6 de esta Ley.» 
la asunción de las tareas legislativas previstas en la Disposición adicional séptima y las medidas de la Disposición adicional primera. Quizá por ese orden.

\section{Aplicación en el ámbito autonómico. País Vasco}

Ciertamente puede considerarse lógico que si en el ámbito estatal no se han dado pasos en la aplicación de la Ley 5/2011 (tras 17 meses de su entrada en vigor) en el autonómico los responsables permanezcan ignaros a tal tarea. Ello está consolidando una especial y curiosa situación de "anomia» de facto pues se dictan leyes y otras normas y resoluciones sobre la materia como si la Ley previa no existiera.

Hemos tenido ocasión de señalar en otros foros ${ }^{5}$ que existen varios campos de acción en el ámbito de las CCAA para la aplicación de la Ley. También que las entidades representativas de la Economía Social de las distintas autonomías pueden, y deben, promover la adopción de medidas en aplicación de esta norma, no siendo necesario esperar y ver lo que se hace desde la Administración central. El carácter de normativa básica establecido en la Disposición final primera de la Ley es sin duda un elemento que debe facilitar la implicación de las CCAA. No nos consta, sin embargo, que se hayan dado grandes pasos en ninguna Comunidad Autónoma en este sentido. En el caso vasco podemos decir que ha habido cal y arena.

Por un lado, el Parlamento Vasco, fundamentalmente a través de su Comisión de Políticas Sociales, Trabajo e Igualdad, ha trabajado en estos meses de vigencia de la Ley 5/2011 de un modo intenso. En ese sentido, se han producido numerosas comparecencias de representantes de las entidades de la Economía Social vasca y también de representantes de las tres universidades vascas y otros estudiosos del tema. A partir de ahí se han producido diversas propuestas de resolución no de Ley que vienen siendo aprobadas ${ }^{6}$. Hay que alabar esta dedicación parlamentaria y sus determinaciones que se refieren expresa y monográficamente a los efectos de esta Ley de Economía Social cuyo carácter de normativa básica sin duda influye, volvemos a insistir, destacadamente.

Pero junto a esto nos encontramos con demostraciones contundentes de lo que venimos denunciando: un entercamiento fáctico inexpli-

5 Pérez de Uralde, José M. ${ }^{\text {a: }}$ opus cit.

6 Boletín del Parlamento Vasco, n. ${ }^{\circ}$ 108, de 15 de abril de 2011. 
cable en ningunear la propia existencia de esta norma en el ejercicio de la actividad legislativa. Algunos ejemplos:

Ley 3/2001, de 13 de octubre, sobre Lanbide-Servicio Vasco de Empleo

Con respecto a esta norma, que fue aprobada 6 meses después de la entrada en vigor de la Ley de Economía Social, nos limitamos a constatar ahora que el término «Economía Social» aparece citado en el artículo 3 de la Ley en relación con las funciones que tiene atribuidas Lanbide-Servicio Vasco de Empleo. Concretamente, el párrafo c) establece como una de esas funciones «Establecer programas de economía social para la creación de empleo estable». Nada más. A la Ley 5/2011 no se la menciona, si bien es verdad que sería excesivamente puntilloso reclamarlo ya que podemos entender que se incluye en el párrafo x) del citado artículo 3 que también considera como función de este organismo «Desarrollar cualesquiera otras funciones que en materia de políticas de empleo e inserción le atribuyan las leyes, el Gobierno Vasco o que se deriven de las transferencias, delegaciones o encomiendas efectuadas por el Gobierno del Estado».

El objeto de crítica por nuestra parte es lo que se refiere a la composición del Consejo de Administración de Lanbide-Servicio Vasco de Empleo, regulado en el artículo 7 de su Ley. En este tema si somos beligerantes y vindicativos. Este órgano colegiado de gobierno se compone del Presidente/a, Vicepresidente/a, Director/a General, dos vocales nombrados directamente por el Gobierno Vasco, cinco vocales de las organizaciones sindicales y cinco de las organizaciones empresariales más representativas del País Vasco. La Economía Social no tiene sitio en el Consejo. Y debiera tenerlo.

La Ley 5/2011 señala, en su artículo 7.4, que «asimismo, las organizaciones, federaciones o confederaciones representativas de cada Comunidad Autónoma tendrán representación en los órganos de participación institucional de las Administraciones de las Comunidades Autónomas que se ocupen de las materias que afectan a sus intereses económicos y sociales, en la forma en que se prevea por las Comunidades Autónomas». Por su parte, el artículo 8.2 de esta Ley señala que

Los poderes públicos, en el ámbito de sus respectivas competencias, tendrán como objetivo de sus políticas de promoción de la economía social, entre otras, las siguientes: 
d) Promocionar la formación y readaptación profesional en el ámbito de las entidades de la economía social...

g) Involucrar a las entidades de la economía social en las políticas activas de empleo, especialmente a favor de los sectores más afectados por el desempleo, mujeres, jóvenes y parados de larga duración...

Como ya hemos señalado, el Parlamento Vasco ha publicado en su Boletín Oficial, con fecha 15 de abril de 2011, una serie de resoluciones aprobadas por la Comisión de Políticas Sociales, Trabajo e Igualdad de entre la que podemos destacar en este momento la n. 8 que textualmente señala:

El Parlamento Vasco reconoce a las organizaciones representativas de las empresas de la economía social como interlocutores económicos y sociales que deben tener presencia en los órganos de participación institucional de la Comunidad Autónoma vasca.

En ese sentido y en lo relativo a la representación de Lanbide, la actual proposición de ley en trámite en la Cámara vasca deberá fijar definitivamente la participación de las organizaciones representativas de la economía social en el consejo de administración del Servicio Vasco de Empleo.

En línea con lo que venimos diciendo, tal propuesta del propio Parlamento ha sido desatendida por él mismo.

Resulta sintomático, para añadir algún dato más, que la reciente Resolución de 24 de julio de 2012, del Director General de LanbideServicio Vasco de Empleo, por la que se publica la convocatoria de las ayudas para la creación y el sostenimiento de las empresas de inserción correspondiente al año 2012, tampoco haga referencia alguna a la Economía Social ni a su Ley a pesar de que este tipo de empresas están incluidas nominalmente en su artículo 5.

\section{Ley 5/2012, de 23 de febrero, de Entidades de Previsión Social} Voluntaria (EPSV)

El Parlamento Vasco aprobó esta Ley (BOPV de 6/3/2012) casi un año después de la entrada en vigor de la Ley 5/2011 de Economía Social. Y aunque de entrada, y como ejercicio de optimismo, pueda advertirse cierta coincidencia en los números que se asignan a ambas normas, no pasa de ahí la vinculación o coincidencia. Ello merece crítica. 
Esta Ley vasca de EPSV sustituye a la que fue aprobada en 1983 (Ley 25/1983, de 27 de octubre). Ambas normas se sustentan en el título competencial determinado en el artículo 10.23 del Estatuto de Autonomía que se refiere a la competencia exclusiva en materia de cooperativas y mutualidades no integradas en la Seguridad Social. El antiguo texto vinculaba en su amplia Exposición de Motivos de 1983 a estas entidades (consideradas textualmente como «mutualidades») «...con el estado social en el que ha de perdurar la justicia social como principio esencial en la búsqueda de la cohesión social» y que «Las entidades de previsión social voluntaria nacieron para ejercer, sin ánimo de lucro y fuera del régimen público de seguridad social, la previsión social voluntaria encaminada a proteger a las personas afectadas contra circunstancias o acontecimientos de carácter fortuito o previsible. Sus características más importantes se centraron en su objeto o finalidad, la protección frente a contingencias personales como la jubilación o la invalidez fundamentalmente, en la ausencia de ánimo de lucro, en la naturaleza asociativa del vehículo gestor propiciador de la solidaridad, en la igualdad de derechos y obligaciones de los socios en relación con las aportaciones efectuadas, y en el sistema autogestionario que comporta la composición democrática de sus órganos de gobierno».

En esa línea, el nuevo texto legal recientemente aprobado introduce estos mismos principios informadores en su artículo 2. Por ello, no podemos dudar de dos cosas básicas, las EPSV que ahora se regulan son las mutualidades que también se regularon antes y que esos principios anunciados se están refiriendo sin duda alguna a la Economía Social, coincidiendo en lo básico con lo que la Ley 5/2011 determina en su artículo 4. Entonces, ¿porqué no hay ni una sola mención al término jurídico «Economía Social» o a la Ley que lo regula? Con respecto a la primera Ley podemos razonablemente explicar que entonces (1983) ese término era poco o nada utilizado y escasamente definido en realidad. Pero en los actuales momentos en los que el término y su concepto han sido estudiados y elaborados científicamente de un modo exhaustivo y hay una Ley que lo regula, la justificación simplemente es imposible. Algún planteamiento pudiera mantener que en realidad el legislador no ha querido regular una figura de la Economía Social, sustrayendo las EPSV de tal concepto y familia. Pero eso es inasumible, especialmente ahora. Por un lado, porque la propia Ley 5/2012 sobre EPSV denomina a estas, aunque solo un par de veces en la Exposición de Motivos, como «mutualidades»y, por otro, porque en el ámbito estatal este figura de las Entidades de Previsión están reguladas con las 
mismas características ${ }^{7}$. Por tanto, la utilización de uno u otro nomen iuris (principio de irrelevancia o de primacía de la realidad) no afecta en absoluto a su consideración conceptual de las EPSV en el seno de la Economía Social y en vinculación directa con la Ley 5/2011. El término «Entidad de Previsión Social» tiene su origen en la España de los años 40, según ha estudiado intensamente el profesor Calvo Vergez ${ }^{8}$, sirviendo entonces para agrupar a todas las entidades mutualistas tanto de carácter social, como de seguro obligatorio o de subsidios también obligatorios, quedando agrupadas en la Confederación Nacional de Montepíos, Mutualidades y Entidades Gestoras y colaboradoras de Previsión Social, adquiriendo en 1948 el nombre de «Confederación Nacional de Entidades de Previsión Social». Según Calvo Vergez: «Podríamos estimar por tanto que la expresión Entidades de Previsión Social constituye únicamente un término administrativo destinado a encuadrar a todas aquellas entidades que desarrollan un tipo concreto de actividad aseguradora delimitada por la especial naturaleza de los riesgos susceptibles de quedar cubiertos, de carácter social, y por la característica concreta de carecer de ánimo de lucro. Todo ello con independencia de que hubiera adoptado la denominación de montepío, mutualidad, sociedad de socorros mutuos, etc...» ${ }^{9}$. En ese sentido, podemos resaltar que la Ley vasca de EPSV incluye dentro de su ámbito «...las sociedades civiles de ayuda mutua, cofradías, montepíos y hermandades, que históricamente han existido en el ámbito agrario, pesquero y ganadero del País Vasco... ${ }^{10}$

Es decir, estamos sin duda alguna ante las mutualidades de la Economía Social y, aun ante otras figuras de las señaladas en el artículo 5 de la Ley 5/2011 de Economía Social.

El hecho de que esta Ley de EPSV, como se ha dicho antes, fuese aprobada y promulgada casi un año después de la entrada en vigor de la de Economía Social, cuyo carácter de normativa básica le infunde especial relevancia ${ }^{11}$, hace muy poco comprensible y aceptable tan clamoroso olvido por parte del legislador vasco. No es nuestra inten-

7 RD Legislativo 6/2004, de 19 de octubre, de Texto Refundido de la Ley de Ordenación y Supervisión de los Seguros Privados (LOSSP). RD 2486/1988, de 20 de noviembre, y RD 1430/2002, de 27 de diciembre (ambos reglamentos de aplicación a estas entidades).

8 Calvo Vergez, Juan: Mutualidades de Previsión Social. Aspectos mercantiles y fiscales. Edit. Dykinson, 2009.

9 Calvo Vergez, Juan: opus cit.

10 Exposición de Motivos de la Ley 5/2012, de 23 de febrero, sobre Entidades de Previsión Social Voluntaria.

11 Lo volvemos a repetir a pesar de la cansina insistencia. 
ción asomarnos al análisis de las posibles causas de este error, pero a una conclusión si nos atrevemos a llegar: no se ha asumido, como debiera haberse hecho, el carácter integrador y básico de la Ley 5/2011, perjudicando con ello su valoración general, conocimiento y promoción. Hubiese sido un gran paso adelante, una auténtica innovación, que esta Ley vasca de EPSV enmarcara a estas entidades en el ámbito de la Economía Social. Y hubiera sido un acierto hacer referencia a la Ley 5/2011, de Economía Social. Con ello se cumpliría mejor con uno de los propósitos de la propia Ley 5/2012 de EPSV cuando señala en su Exposición de Motivos que "Todo ello, unido a las demandas que impone la realidad social, es lo que aconseja, junto con la necesaria adecuación de los supuestos contemplados en la ley al correcto tratamiento tributario y fiscal dentro del ámbito de las haciendas forales y en el seno del Concierto Económico, que se lleve a cabo una actualización de la normativa vigente, incorporando todas las novedades que en el campo del Derecho europeo y del Derecho interno estatal y autonómico vienen exigidas por el buen hacer legislativo, en lo que representa el núcleo estructural y funcional de la materia regulada». A ese respecto, la Ley no cumple con tal propósito con respecto a la Economía Social.

Ley 8/2012, de 17 de mayo, del Consejo Económico y Social Vascol Euskadiko Ekonomia eta Gizarte Arazoetarako Batzordea (CES)

También más de un año después de haber entrado en vigor la multicitada Ley 5/2011 de Economía Social se aprobaba y publicaba esta Ley de reforma del CES vasco que en su Exposición de Motivos se justifica «... mediante la introducción de determinadas modificaciones en la normativa que hasta el momento ha venido regulando sus funciones, composición y funcionamiento».

Como ha de imaginarse, pues de lo contrario no haríamos referencia a esta norma, el término «Economía Social» o alguna referencia a su Ley vuelven a estar radicalmente ausentes del texto. Ausencia que tampoco tiene justificación alguna. En ese sentido, podemos enunciar, siquiera someramente, algunas razones para haber incluido estas referencias:

a) En la Exposición de Motivos de la norma se indica, refiriéndose a la composición del CES vasco, que "Respecto a su composición, se delimitan con mayor precisión las personas que integran el grupo tercero, introduciendo una representación del denominado tercer sector de acción social...». Por su parte, en el artículo 4.1 de esta Ley del CES se es- 
tablece esta composición incluyendo en su párrafo c) lo que se ha dado en llamar "grupo tercero», o si se quiere "cajón de sastre» (en denominación libre). Tal grupo se compone de una persona representante respectivamente de los

....sectores, instituciones, entidades o asociaciones de la Comunidad Autónoma del País Vasco siguientes:

1. Cámaras de Comercio, industria y navegación.

2. Cajas de ahorro y entidades financieras.

3. Cooperativas.

4. Sociedades anónimas laborales.

5. Organizaciones pesqueras.

6. Organizaciones agrarias.

7. Organizaciones de Consumidores.

8. Organizaciones del tercer sector de acción social.

Desde hace ya tiempo el Ilamado «Tercer Sector de Acción Social» está indiscutiblemente considerado por la doctrina científica como parte integrante de la Economía Social, refiriéndose a él como el «núcleo duro y sustantivo» de los productores no de mercado de la Economía Social12. El CES vasco no puede ser tenido por ignorante de estos temas pues en su propia Memoria Anual (2011) en el apartado 5 de su Capítulo II analiza "Las cuentas de la economía social en la CAPV», haciendo expresa referencia a la distinción de las dos grandes partes que forman este sector: «a) la de mercado o empresarial y b) la de productores no de mercado, también conocido como tercer sector». Por cierto, es precisamente en este apartado de la Memoria del CES vasco donde encontramos por primera vez una referencia expresa a «La recién aprobada Ley 5/2011, de 29 de marzo, de Economía Social». Referencia que descansa pacíficamente en nota a pie de página.

A veces pareciera que mencionar la Ley o a la Economía Social por su nombre generase cierto temor a sufrir algún tipo de urticaria o mal mayor. Sino no se entiende que las cooperativas, las sociedades laborales, las organizaciones del tercer sector de acción social y seguramente también algunas de las llamadas «organizaciones pesqueras» y de las

12 Monzón Campos, José Luís (Director). «La Economía Social en España en el año 2008. Ámbito, magnitudes, actividades y tendencias». Edit. CIRIEC-España, Ministerio de Trabajo e Inmigración, Observatorio español de la Economía Social y Fundación ONCE. Valencia, 2010. También: Etxazarreta Etxarri, Enekoitz y Morandeira Arca, Jon. «Consideraciones conceptuales sobre la Economía Social a la luz de la Ley 5/2011». Revista Vasca de Economía Social n. ${ }^{\circ}$, pp. 8 a 36. Edit. Instituto GEZKI de la UPV/EHU y Gobierno Vasco. Bilbao, 2012 
«organizaciones agrarias» que forman parte de la Economía Social, tal y como especifica el artículo 5 de su Ley, nunca se mencionen como parte de este sector. Lo más correcto hubiera sido situar directa y expresamente a la Economía Social en el CES vasco a través, eso si, de los representantes de las organizaciones y entidades que la componen (mencionando después de manera específica a las cooperativas, sociedades laborales, etc...). No hacerlo desprecia las resoluciones del Parlamento Vasco y, sobre todo, lo prescrito en los mencionados artículos 7.4 y 8 de la Ley de Economía Social.

No insistimos más (por ahora). Solo nos queda contestar a la pregunta que preside estas reflexiones: la aplicación de la Ley 5/2011 de Economía Social es obligación de todos, pero indudablemente de unos más que de otros (sin retórica). 